\title{
Alteration of Ovalbumin Immunogenic Activity by Glycosylation through Maillard Reaction
}

\author{
Yasuko Kato, Tsukasa Matsuda, ${ }^{*}$ Kenji Watanabe* \\ and Ryo NAKAMURA* \\ Women's College of Tokaigakuen, \\ Tenpaku-ku, Nagoya 468, Japan \\ *Department of Food Science and Technology, Faculty of Agriculture, \\ Nagoya University, Chikusa-ku, Nagoya 464, Japan
}

Received July 17, 1984

\begin{abstract}
The immunogenic properties of glycosylated ovalbumin were investigated by measuring specific IgE and IgG antibody responses in mice. Ovalbumin was glycosylated with glucose through Maillard reaction. The glycosylated protein reacted well with the antibody to native ovalbumin. The glycosylated and native ovalbumins were injected into mice, and serum IgE and IgG responses were determined by the passive cutaneous anaphylaxis (PCA) test and a solid phase enzyme immunoassay (ELISA). The glycosylated ovalbumin induced rather lower responses of both IgE and $\mathrm{IgG}$ antibodies than native ovalbumin did, and the antibody directed against glycosylated ovalbumin reacted with native protein. These results suggested that immunogenic properties of proteins could be altered by the glycosylation through Maillard reaction.
\end{abstract}

Reducing sugars react with proteins through Maillard reaction, resulting in protein glycosylation. Such non-enzymatic glycosylation of proteins has been investigated widely in view of the nutritional and functional properties of foods containing proteins and reducing sugars. ${ }^{11}$ Physical and chemical properties of proteins were reported to be altered by such a glycosylation. ${ }^{2,3)}$ It has also been reported that the glycosylation of lysine residues under physiological conditions occurred for proteins with relatively slow turnover rates, such as collagen, lens crystalline and hemoglobin, and that the functions of proteins were altered by the glycosylation. ${ }^{4,5}$

$\beta$-Lactoglobulin lactosylated by Maillard reaction was reported to be more allergic than the native protein for patients with cow's milk hypersensitivity ${ }^{6}{ }^{6}$ Furthermore, it has recently been reported that the lactose attached to $\beta$ lactoglobulin could be a new antigenic site. ${ }^{7)}$ However, immunogenic properties of proteins glycosylated by Maillard reaction are still uncertain.

On the other hand, many attempts have been made to alter the immunochemical properties of protein antigens by several chemical modification. ${ }^{8,9)}$ From this point of view, it is of interest to examine the immunogenic properties of glycosylated proteins.

In this study, to elucidate the immunogenic properties of ovalbumin glycosylated with glucose through Maillard reaction, the IgE and IgG antibody responses in mice were examined for the native and glycosylated proteins, and the reactivity between the native and glycosylated proteins, and the reactivity between the native protein and antibodies produced against glycosylated proteins was investigated.

\section{MATERIALS AND METHODS}

Glycosylation of ovalbumin with glucose. Ovalbumin (OV) was prepared from fresh egg white of White Leghorn hens by the ammonium sulfate method. ${ }^{10)}$ Freeze-dried OV was dissolved in distilled water and mixed with Dglucose $(30 \%$ of OV dry weight), and the mixture was freeze-dried again after adjustment to $\mathrm{pH} 8.0$ with dil. $\mathrm{NaOH}$. The dried sample was kept for 2 or 7 days at $50^{\circ} \mathrm{C}$ and $65 \%$ relative humidity maintained with saturated $\mathrm{KI}$ 
solution.

Polyacrylamide gel electrophoresis. Gel electrophoresis (7.5\% acrylamide) was performed according to the method of Davis. ${ }^{11)}$ The gel sheets were stained with $0.2 \%$ Coomassie Brilliant Blue R-250.

Immunodiffusion and immunoelectrophoresis. Ouchterlony immunodiffusion ${ }^{12)}$ was carried out in $1.2 \%$ agarose in phosphate buffered saline (PBS) containing $0.1 \% \mathrm{NaN}_{3}$. Immunoelectrophoresis was performed in $1.0 \%$ agarose (FMC Corp.) in barbital buffer $(I=0.025)$. After electrophoresis of antigens $(4 \sim 8 \mu \mathrm{g})$, the rabbit antiserum was allowed to diffuse from the trough between the wells. After incubation at $25^{\circ} \mathrm{C}$ for $30 \mathrm{hr}$, the gel plates were washed with PBS for 3 days, and then stained with $5 \%$ Amino Black 10B in methanol-acetic acid $(9: 1$, by vol.) and destained with $2 \%$ acetic acid.

Immunization of mice. Seven mice (ddY, 6- to 8-week old, male; Shizuoka Agric. Coop. for Labo. Animals) were immunized by intraperitoneal injection of $1 \mu \mathrm{g}$ of protein antigen in $100 \mu$ l of PBS with Freund's complete adjuvant at a water-oil ratio of $1: 1$. The mice received a booster injection of $1 \mu \mathrm{g}$ of the antigen mixed with $1 \mathrm{mg}$ of $\mathrm{Al}(\mathrm{OH})_{3}$ in $500 \mu \mathrm{g}$ of PBS, 4 days after the first immunization. Blood was collected 8 and 24 days after the first immunization by puncturing of the retro-orbital venous plexus. The serum was separated from the pooled blood of seven mice, and stored at $-80^{\circ} \mathrm{C}$ before use.

Passive cutaneous anaphylaxis (PCA) test. The IgE antibody titer was determined by the heterologous passive cutaneous anaphylaxis reaction in the dorsal skin of male Sprague-Dawley rats. ${ }^{13)}$ One tenth of a mililitter of the pooled sera serially diluted with PBS was injected intradermally into the shaved back of an SD rat. After $3 \mathrm{hr}$, the rat was challenged by intravenous injection of $1 \mathrm{mg}$ of each antigen in $1 \mathrm{ml}$ of $0.5 \%$ Evans blue dye dissolved in PBS. After $30 \mathrm{~min}$ the rat was decapitated and the dorsal skin was flayed. The antibody titer was expressed as the reciprocal of the highest dilution yielding a positive skin reaction blue spot of more than $5 \mathrm{~mm}$ diameter.

Enzyme linked immunosorbent assay (ELISA). The serum IgG antibody was measured by a plate-binding ELISA. ${ }^{14)}$ Flat-bottomed microtiter-plates were coated with an appropriate concentration of antigen, and the mouse IgG antibody which reacted with plate binding antigens was determined by using peroxidase-coupled goat anti-mouse IgG (Cappel) as described previously. ${ }^{15}$ )

Analytical methods. The protein concentration was determined by the method of Lowry et $a l^{16)}$ with OV $\left(E_{1 \mathrm{~cm}}^{1 \%}=7.5\right)$ as standard. The free amino groups were measured by the fluorometric method ${ }^{17)}$ as described previously. ${ }^{18)}$
$C D$ spectra measurement. CD spectra were measured with a Jasco J-40A spectropolarimeter. The data were expressed as mean residue ellipticities, assuming a mean residue weight of 111 on the basis of the amino acid composition of ovalbumin.

\section{RESULTS}

The OV kept for 2 or 7 days with glucose was applied to a column of Sephadex G-150. As shown in Fig. 1, some polymerized components were produced during the 7 day glycosylation process. The polymerized fraction of the 7-day sample eluted at the void volume and the last eluted fraction of the 2-day sample were collected separately and called $\mathrm{OVG}_{\mathrm{p}}$ and $\mathrm{OVG}_{\mathrm{m}}$, respectively. The OVG samples were stored at $-80^{\circ} \mathrm{C}$ before use.

The free amino group contents of OVG samples were determined by fluorometric analysis with fluorescamine, and those of $\mathrm{OVG}_{\mathrm{p}}$ and and $\mathrm{OVG}_{\mathrm{m}}$ were $35 \%$ and $45 \%$ of that of native $\mathrm{OV}$, respectively.

Figure 2 shows an electrophoretogram of OVG samples. $\mathrm{OVG}_{\mathrm{p}}$ consisted of various polymerized components and some of them

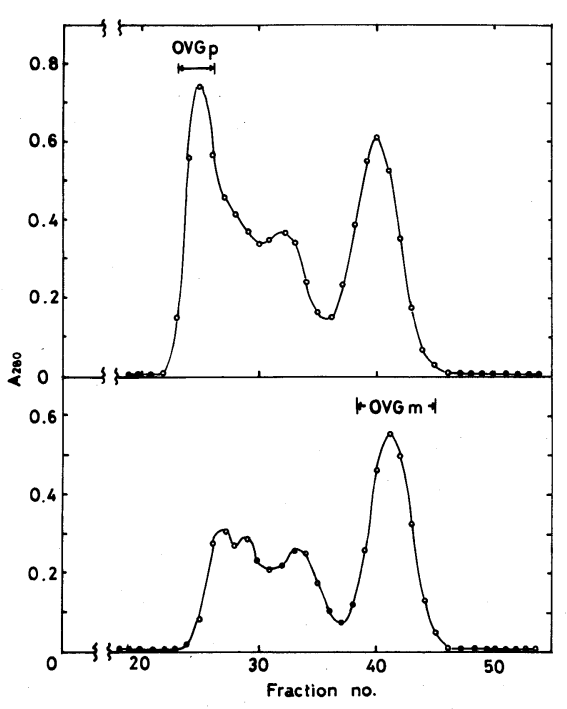

FIG. 1. Gel Filtration of Ovalbumins Glycosylated with Glucose.

Ovalbumin kept with glucose for 2 (lower) and 7 (upper) days were applied to a column of Sephadex G-150 and eluted with PBS. The fractions of $\mathrm{OVG}_{\mathrm{p}}$ and $\mathrm{OVG}_{\mathrm{m}}$ were pooled and used for the following experiments. 


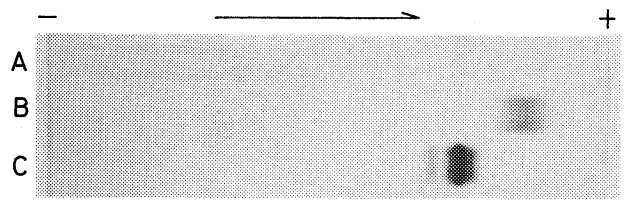

FIG. 2. Polyacrylamide Gel Electrophoresis of Glycosylated Ovalbumins.

$\mathrm{OVG}_{\mathrm{p}}, \mathrm{OVG}_{\mathrm{m}}$ and $\mathrm{OV}$ were applied to lanes $\mathrm{A}, \mathrm{B}$ and $\mathrm{C}$, respectively.

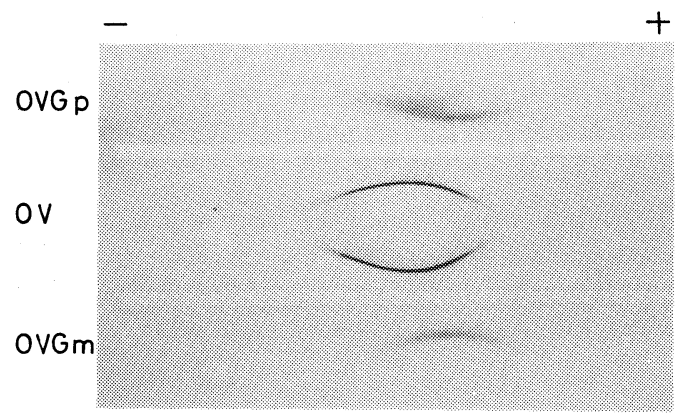

FIG. 3. Immunoelectrophoresis of Glycosylated Ovalbumins.

The rabbit anti-OV serum ( $50 \mu \mathrm{l}$; Cappel) was allowed to diffuse from each trough against $\mathrm{OVG}_{\mathrm{p}}, \mathrm{OVG}_{\mathrm{m}}$ and $\mathrm{OV}$ which had migrated electrophoretically.

were too large to migrate into the lower gel. $\mathrm{OVG}_{\mathrm{m}}$ gave a protein band with a little greater mobility than that of native $\mathrm{OV}$ due to the blocking of positively charged amino groups. In the electrophoretogram of either OVG sample, no protein band corresponding to native $\mathrm{OV}$ was detected at all.

The reactivity of $\mathrm{OVG}_{\mathrm{p}}$ and $\mathrm{OVG}_{\mathrm{m}}$ with anti-OV antibody was examined by immunoelectrophoresis to determine whether the natural antigenicity of $\mathrm{OV}$ was destroyed by the glycosylation treatment. As shown in Fig. 3, both $\mathrm{OVG}_{\mathrm{p}}$ and $\mathrm{OVG}_{\mathrm{m}}$ produced broad precipitin arcs with a little greater mobility, and the precipitin arc of $\mathrm{OVG}_{\mathrm{p}}$ appeared to contain another minor precipitin arc.

The conformational changes of $\mathrm{OV}$ molecules induced by the glycosylation treatment were examined by $C D$ spectrum analysis. Figure 4 shows the CD spectra of $\mathrm{OV}, \mathrm{OVG}_{\mathrm{p}}$ and $\mathrm{OVG}_{\mathrm{m}}$. $\mathrm{OVG}_{\mathrm{m}}$ showed a spectrum with a negative maximum at $222 \mathrm{~nm}$, which was al-

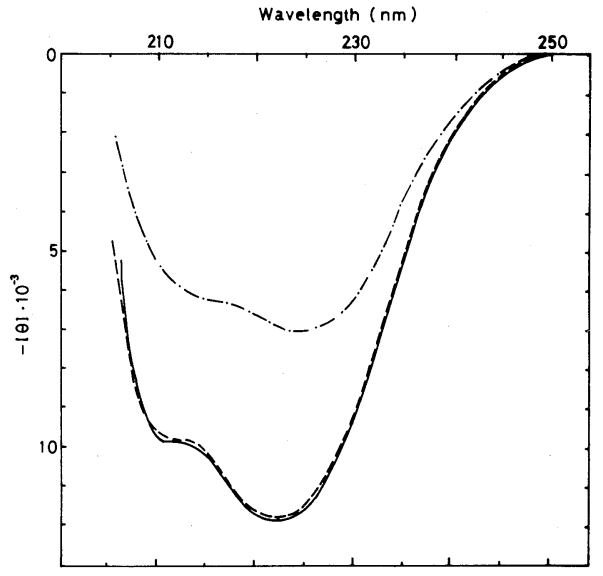

FIG. 4. CD Spectra of Glycosylated Ovalbumins.

$\left.\mathrm{OVG}_{\mathrm{p}}(----), \mathrm{OVG}_{\mathrm{m}}(--)^{--}\right)$and OV (- - were dissolved in PBS $(200 \sim 300 \mu \mathrm{g} / \mathrm{ml})$ and the CD spectra were measured at room temperature.

most the same as for the native one. However, the ellipticity of $\mathrm{OVG}_{\mathrm{p}}$ was rather weaker between 205 and $230 \mathrm{~nm}$ than that of the native one.

The $\mathrm{IgE}$ and $\mathrm{IgG}$ antibody responses were examined 8 and 24 days after the first immunization, and the anitbody production for each sample was compared. As shown in Fig. 5(A), the mice immunized with OV showed a higher PCA titer of 320, whereas the mice immunized with the OVG samples showed rather lower titers. Especially, no positive reaction was detected with the serum of $\mathrm{OVG}_{\mathrm{m}}$-immunized mice under these experimental conditions. The $\mathrm{IgE}$ antibodies produced against $\mathrm{OV}$ and $\mathrm{OVG}$ were decreased and increased, respectively, 24 days after the first immunization as shown in Fig. 5(B). Nevertheless, the IgE antibody titer of the OV-immunized mice serum was higher than that of the OVG-immunized mice sera. As shown in Fig. 5(C), only a trace amount of sepcific IgG antibody was detected in all sera 8 days after the first immunization. Twenty-four days after the immunization, the IgG antibody titer of $\mathrm{OVG}_{\mathrm{m}}$-immunized mice serum was rather lower than that of the OV-immunized mice serum, whereas the titer of $\mathrm{OVG}_{\mathrm{p}}$ immunized mice serum was much higher than that of the OV-immunized mice serum, as 


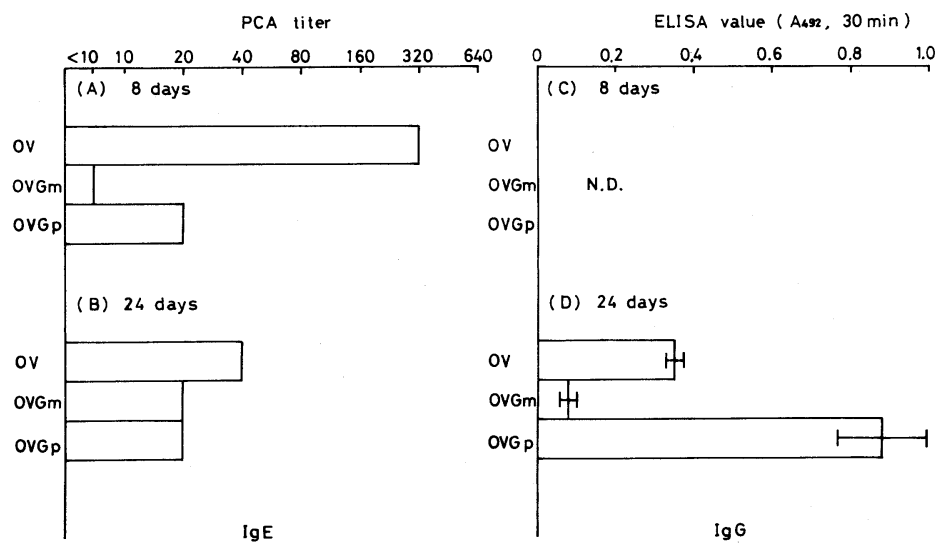

Fig. 5. IgE and IgG Antibody Responses to $\mathrm{OVG}_{\mathrm{p}}, \mathrm{OVG}_{\mathrm{m}}$ and $\mathrm{OV}$.

$\mathrm{IgE}$ and IgG responses are expressed as PCA titers and ELISA values, respectively. The protein concentrations of ELISA coating solutions were 10,100 and $100 \mu \mathrm{g} / \mathrm{ml}$ for $\mathrm{OVG}_{\mathrm{p}}, \mathrm{OVG}_{\mathrm{m}}$ and $\mathrm{OV}$, respectively, which were enough for each serum to give the highest ELISA value. In the sera collected 8 days after immunization, specific $\operatorname{IgG}$ was not detected (N.D.). The ELISA values represent mean \pm S.D. of 3 determinations.

Table I. Reactivity Between OV AND IgE ANTIBODIES DiRECTED AGAINST OVGp AND OVGm

\begin{tabular}{rll}
\hline Antiserum & Antigen & PCA titer \\
\hline \multirow{2}{*}{ anti-OVG } & & 20 \\
& $\mathrm{OVG}_{\mathrm{p}}$ & 20 \\
anti-OVG & $\mathrm{OV}$ & 20 \\
& $\mathrm{OVG}_{\mathrm{m}}$ & 20 \\
\hline
\end{tabular}

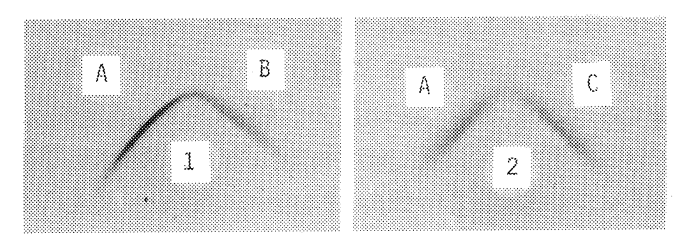

FIG. 6. Ouchterlony Immunodiffusion of Antisera Directed against Glycosylated Ovalbumins.

Mouse anti-OVG $\mathrm{m}_{\mathrm{m}}(1)$ and anti-OVG $\mathrm{P}_{\mathrm{p}}(2)$ sera were allowed to diffuse against $\mathrm{OV}(\mathrm{A}), \mathrm{OVG}_{\mathrm{m}}(\mathrm{B})$ and $\mathrm{OVG}_{\mathrm{p}}$ (C).

shown in Fig. 5(D).

The reactivity of anti-OVG antibodies with native $\mathrm{OV}$ was investigated by using mouse sera collected 24 days after the first immunization. As shown in Table I, the PCA titers of anti-OVG $\mathrm{OV}_{\mathrm{p}}$ and anti-OVG $\mathrm{m}$ sera found on challenging with native $\mathrm{OV}$ were the same as that on challenging with $\mathrm{OVG}_{\mathrm{p}}$ or $\mathrm{OVG}_{\mathrm{m}}$ itself, respectively. Figure 6 shows the immunodiffusion of anti-OVG $\mathrm{OV}_{\mathrm{m}}$ and $\mathrm{ant}-\mathrm{OVG}_{\mathrm{p}}$ sera against $\mathrm{OV}, \mathrm{OVG}_{\mathrm{m}}$ and $\mathrm{OVG}_{\mathrm{p}}$. The antibodies to OVG formed a precipitin line also against $\mathrm{OV}$, and no spur was detected between the two precipitin lines of $\mathrm{OV}$ and $\mathrm{OVG}$.

\section{DISCUSSION}

OV was modified by the glycosylation with glucose, and the modified OVG samples were characterized immunochemically and physicochemically (Figs. 3 and 4). The conformation of the polymerized protein, $\mathrm{OVG}_{\mathrm{p}}$, seemed to be a little different from that of the native one, but the change was not so serious as to cause the loss of immunoreactivity to anti-native protein antibody. The results of immunoelectrophoresis and $\mathrm{CD}$ analyses of $\mathrm{OVG}_{\mathrm{m}}$ suggested that the monomer type of glycosylated protein $\mathrm{OVG}_{\mathrm{m}}$ was not so different in conformation from the native one except that some side chains were glycosylated.

The glycosylation of $\mathrm{OV}$ with glucose strongly suppressed the antibody response in mice, especially the specific IgE production (Fig. 5). It seemed reasonable to say that this 
suppressive effect was due to glucose attached to $\mathrm{OV}$ molecules, rather than to conformational changes of $\mathrm{OV}$, because little or no difference was found between the CD spectra of $\mathrm{OVG}_{\mathrm{m}}$ and $\mathrm{OV}$ as described above. Abuchowski et al. ${ }^{8)}$ reported that modified proteins without immunogenicity could be prepared by attaching polyethyleneglycol (MW: 780 2000) to protein amino groups. The polyethyleneglycol and glucose used for the protein modification possess a common carbohydrate characteristic, but they are quite different in molecular weight. The mechanism of such a suppressive effect on the immune response is uncertain, but it could be said that the protein modification with nonimmunogenic compounds like glucose or polyethyleneglycol was effective for the immune response suppression.

The glycosylated and polymerized protein, $\mathrm{OVG}_{\mathrm{p}}$, suppressed the IgE response as well as $\mathrm{OVG}_{\mathrm{m}}$. On the contrary, the IgG response was stronger to $\mathrm{OVG}_{\mathrm{p}}$ than $\mathrm{OV}$ (Fig. 5). It is interesting to note that $\mathrm{OVG}_{\mathrm{p}}$ induced quite the reverse effect depending on the antibody class. The increase in molecular size caused by polymerization might be responsible for the stronger immunogenic activity of $\mathrm{OVG}_{\mathrm{p}}$ for IgG antibody production, because larger particle antigens are generally good immunogens.

It has been considered to be quite difficult to alter the immunogenic properties of proteins like enzymes by chemical modifications without loss of their biological activity. Though OV has no biological activity, the serius conformational changes did not seem to be caused by the 2 day glycosylation process through Maillard reaction (Figs. 3 and 4). Furthermore, the antibodies produced against OVG reacted well with the native protein (Table I and Fig. 6), suggesting that the na- tural antigenicity of OVG was not so different from that of the native one. Thus, the glycosyaltion of proteins through Maillard reaction would be a good tool for altering protein immunogenic activity. Further studies on the immunogenic properties of glycosylated proteins are in progress.

\section{REFERENCES}

1) C. Ericksson, "Maillard Reaction in Food, Progress in Food and Nutrition Science Ser., Vol. 5," Pergamon Press, New York, 1981.

2) P. T. Tybor, C. W. Dill and W. A. Landmann, $J$. Food Sci., 38, 4 (1973).

3) Y. Kato, K. Watanabe and Y. Sato, J. Food Sci., 46, 1835 (1981).

4) S. P. Robins and A. J. Bailey, Biochem. Biophys. Res. Commun., 48, 76 (1972).

5) N. Shaklai, R. L. Garlick and H. F. Bunn, J. Biol. Chem., 259, 3812 (1984).

6) E. Bleumink and E. Young, Int. Arch. Allergy, 34, 521 (1968).

7) H. Otani and F. Tokita, Jpn. J. Zootech. Sci., 53, 344 (1982).

8) A. Abuchowski, T. Van Es, N. C. Palczuk and F. F. Davis, J. Biol. Chem., 252, 3578 (1977).

9) J. 'R. Uren and R. C. Ragin, Cancer Res., 39, 1927 (1979).

10) R. D. Marshall and A. Neuberger, "Hen's Egg Albumin," in Glycoproteins, ed. by A. Gottschalk, Elsevier, Amsterdam, 1972, p. 732.

11) B. J. Davis, Ann. N.Y. Acad. Sci., 121 (1964).

12) O. Ouchterlony, Acta Pathol. Microbiol. Scand., 32, 231 (1952).

13) I. Mota and D. Wong, Life Sci., 8, 813 (1969).

14) E. Engvall and P. Perhann, Immunochemistry, 8, 871 (1971).

15) T. Matsuda, K. Watanabe and R. Nakamura, Biochem. Biophys. Res. Commun., 110, 75 (1983).

16) O. H. Lowry, N. J. Rosebrough, A. L. Farr and R. J. Randall, J. Biol. Chem., 193, 265 (1951).

17) P. Böhlen, S. Stein, W. Dairman and S. Undenfriend, Arch. Biochem. Biophys., 155, 213 (1973).

18) Y. Kato, K. Watanabe and Y. Sato, J. Agric. Food Chem., 29, 540 (1981). 